\title{
A Study of Software Testing: Categories, Levels, Techniques, and Types
}

\author{
Mubarak Albarka Umar \\ School of Computer Science and Technology, \\ Changchun University of Science and Technology, \\ 7186 Weixing Road, Jilin, China \\ Email:2018300037@mails.cust.edu.cn
}

\begin{abstract}
Software Testing is the process of evaluating a software program to ensure that it performs its intended purpose. Software testing verifies the safety, reliability, and correct working of software. The growing need for quality software makes software testing a crucial stage in Software Development Lifecycle. There are many methods of testing software, however, the choice of method to test a given software remains a major problem in software testing. Although, it is often impossible to find all errors in software, employing the right combination of methods will make software testing efficient and successful. Knowing these software testing methods is the key to making the right selection. This paper presents a comprehensive study of software testing methods. An explanation of Testing Categories was presented first, followed by Testing Levels (and their comparison), then Testing Techniques (and their comparison). For each Testing Levels and Testing Techniques, examples of some testing types and their pros and cons were given with a brief explanation of some of the important testing types. Furthermore, a clear and distinguishable explanation of two confused and contradictory terms (Verification and Validation) and how they relate to Software Quality was provided.
\end{abstract}

Keywords: Software Testing, Testing Categories, Testing Levels, Testing Techniques, Testing Types, Software Quality, Verification and Validation.

\section{INTRODUCTION}

Software testing is an integral phase in Software Development Life Cycle (SDLC) process [1], it involves many technical and non-technical aspects (such as specification, design, implementation, installation, maintenance and management issues) in software engineering [2]. Around 50\% of software projects' development time and effort are put in software testing [3], [4], [2]. Software testing is defined as the process of evaluating a software program with the intent of finding fault or errors in software. Testing is done to; ensure that a software performs its intended purpose correctly [3], access, achieve and preserve quality of a software [4], [5], and thereby verify that the software is fit for use [2]. In SDLC, a software is not considered finished until it has passed its testing [6] and the earlier an error is detected, the cheaper it is to fix it. The overall purpose of testing is not to demonstrate that software is free of errors but to give confidence that the software is working well before installation.

The "software we write [develop] today potentially touches millions of people" [3] across various walks of life and has become an integral part of our routines, this indicates the need for safe and reliable software. Unfortunately, humans are prone to err, and so the fundamental facts of humans' core involvement in software development makes errors an inevitable inclusion in a software [4]. Software errors (bugs) can cause serious effects in live operation [4] and even death [7]. It is important to treat such errors early because they get costlier with progress in the development phase. For instance; a report released by the National Institute of Standards and Technology (NIST) estimated that software bugs are costing the USA economy $\$ 59.5$ billion annually [8], Jones also highlighted in his survey [9] that $\$ 500$ billion is lost annually due to poor software quality and the cost be reduced through testing the software. The eminent and massive effects of software bugs cannot be overestimated and hence, the need for software to be tested before delivered.

In the context of Software Quality, Verification and Validation (V\&V) are often confusing terms. However, testing help in achieving quality software through Verification and Validation (V\&V) methods. Verification is a Quality Control (QC) process that is concerned about building the software right, and Validation is a Quality Assurance (QA) process that is concerned with building the right software. Thus, Verification checks the conformity to the standard of software by verifying the correctness of one life cycle's deliverable transformation to the next while Validation checks back against the requirements of the customers. Verification is an internal process which involves set of activities to ensure that software correctly implements specific functions, it is usually done by the development team while, Validation requires some external process and involves set of activities to ensure that the developed software is traceable to customer requirements [10], its mostly done with the stakeholders to provide degree of software assurance. Verification usually begins before Validation and then they run in parallel until the release of the software. The use of $\mathrm{V} \& \mathrm{~V}$ methods during software development helps in early detection of error, and hence, it can be fixed at a low cost [4]. 
There are two testing categories (approaches): Static and Dynamic [2], [11], [12]. There are generally three main software testing techniques which are all under dynamic testing approach [12]: White-box, Black-box and Greybox testing [13], [14], [15]; each of the dynamic testing can be performed at different testing levels and they comprise of several types of testing. There are four general software testing levels: unit testing, integration testing, system testing, and acceptance testing [6], [2], [14],[16] and various types of testing comes under these levels [17].

The remaining part of this paper is organized as follows; Section Two presents the software testing approaches, followed by software testing levels, how they relate to the SDLC process, and their comparison in Section Three. Then in Section Four software testing techniques were thoroughly discussed, their comparison was also provided. Section Five provided a brief explanation of some of the most important types of testing and finally, conclusion was made in Section Six.

\section{TESTING CATEGORIES (APPROACHES)}

Static and Dynamic testing are the two testing approaches that are occasionally inseparable, but are mostly discussed separately [2]. The Static testing approach is done without executing the program and is called "verification activities", while the Dynamic testing approach involves executing the program with real inputs, most of the current literature refer to the dynamic testing as "testing" [11].

Static Testing Approach: involves source code only and it deals with program and symbolic analysis, model checking, error handling, and code inspection to ensure functional requirements, design and coding standards are observed and estimate software quality without any reference to actual executions [2]. Desk checking, Code walkthrough, and Formal inspections are the commonly used techniques here [18], [19].

Dynamic Testing Approach: involves actual code executions [11] to ascertain and/or approximate software quality and it deals with a combination of inputs, use of structurally dictated testing procedures, and automation of testing environment generation [2] to test the internal design of software. Most of the testing we perform are in this category as seen in Figure 1.

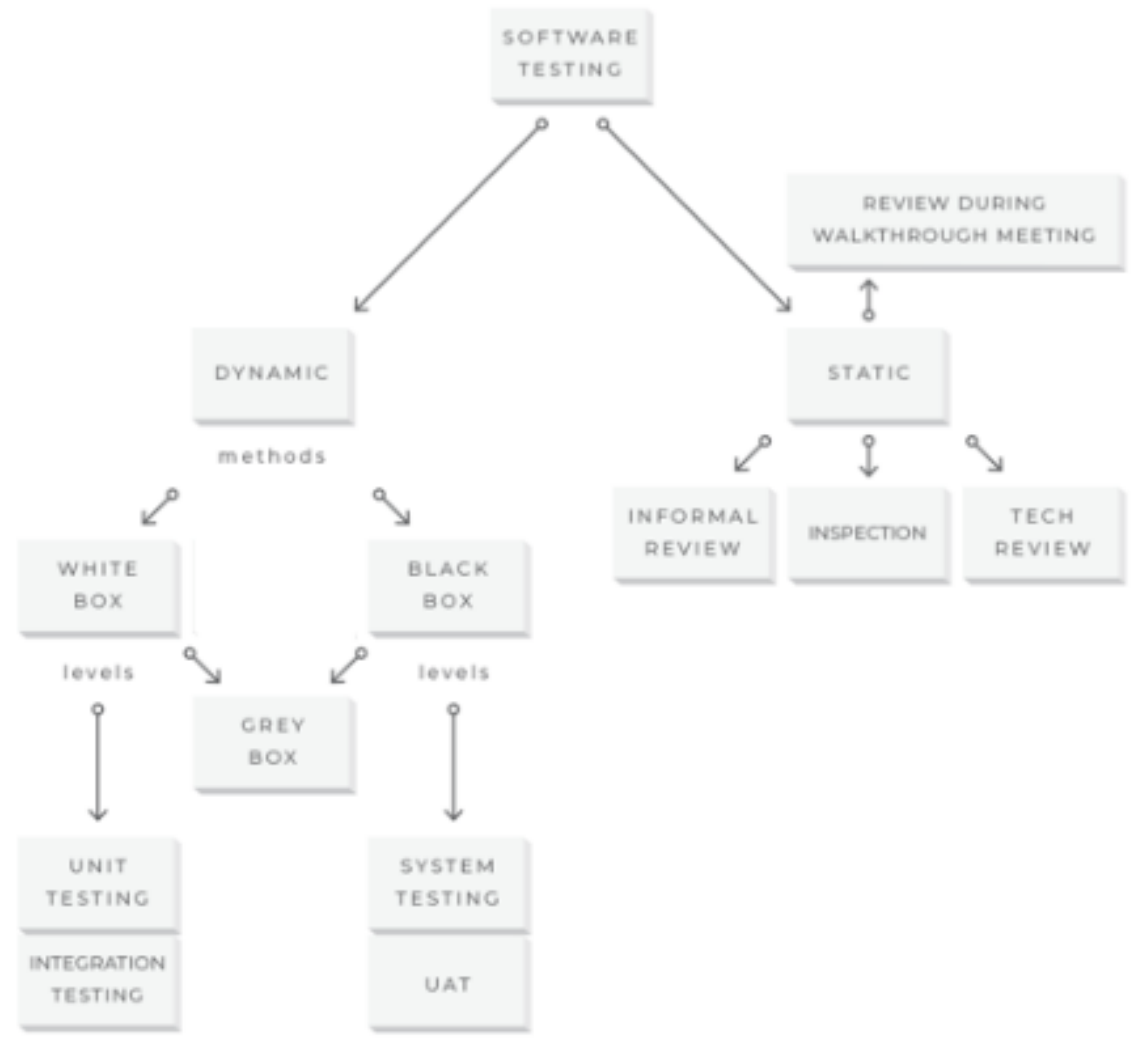

Figure 1: Software Testing Categories

\section{SOFTWARE TESTING LEVELS}

Unit testing: This testing emphases on individual unit or module in isolation. It is a testing in which the smallest testable portion of a software is tested to verify its functionality against its specification. The unit can be a constructor or destructor at class level in object-oriented environment [20] and a structure in procedural programming paradigm. Control-flow testing and data flow testing are some of the types of Unit testing. Unit testing is usually done by developers [6]. 
Integration Testing: involves testing two or more combined units that must work together to ensure an error-free flow of control and data (such as consistency of parameters, file format and soon) among combined units and their overall correct design and integration. User interface, use-case, interaction, and big bang (integrate and test all modules at once) are some of integration testing types. This kind of testing is performed by testers [6].

System Testing: involves testing an integrated complete software to check against its compliance with its requirements. It verifies the overall interaction of components to ensure unanimous working of all modules and programs without error. It involves various types of both functional (tests functionality of software) testing and non-functional (tests quality of software) testing such as performance, reliability, usability, and security testing. System testing is performed by the testing team [6].

Acceptance Testing: This testing is performed to validates the software against customer requirements. This testing is done to ensure that the software does what the customer wants it to do and check the acceptability of the system. User Acceptance Testing (UAT), as sometimes called, comprises of two testing types: Alpha testing: is a testing performed by both development team and users using made-up data, and Beta testing in which users start using the software with real data and carefully observer the software for errors [6].

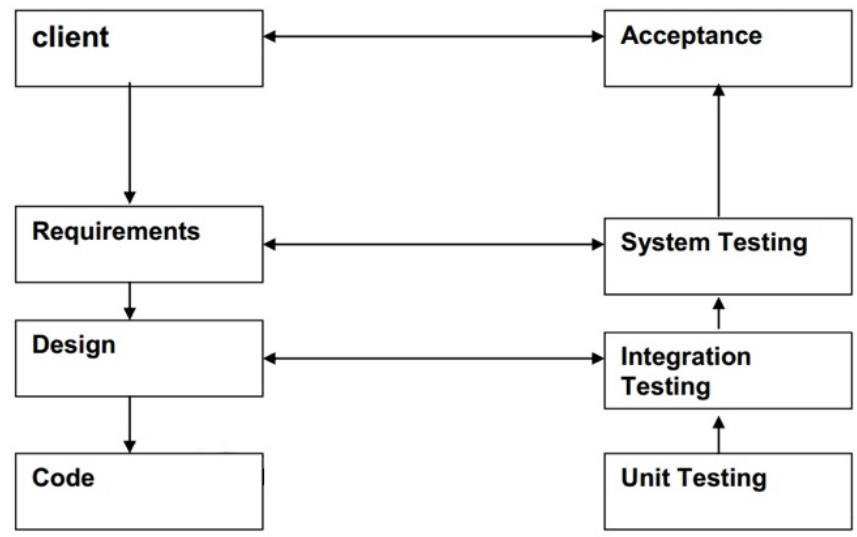

Figure 2: Software Testing Levels

Table 1: The Software Testing Levels compared [12].

\begin{tabular}{|c|c|c|c|c|}
\hline Criteria & Unit & Integration & System & Acceptance \\
\hline Purpose & $\begin{array}{c}\text { Correct working of } \\
\text { unit/module } \\
\text { Correct working } \\
\text { of integrated units }\end{array}$ & $\begin{array}{c}\text { Whole system works } \\
\text { well when integrated }\end{array}$ & $\begin{array}{c}\text { Customer's } \\
\text { expectations are met }\end{array}$ \\
\hline Testing time & Smallest testable part & $\begin{array}{c}\text { Interface and } \\
\text { interaction of } \\
\text { modules }\end{array}$ & $\begin{array}{c}\text { Interaction and } \\
\text { working of all } \\
\text { modules as one }\end{array}$ & $\begin{array}{c}\text { Software working in } \\
\text { accordance with given } \\
\text { specifications }\end{array}$ \\
\hline Performed by & Devitten & $\begin{array}{c}\text { Once new } \\
\text { components are } \\
\text { added }\end{array}$ & $\begin{array}{c}\text { Once software is } \\
\text { complete }\end{array}$ & $\begin{array}{c}\text { Once software is } \\
\text { operationally ready }\end{array}$ \\
\hline $\begin{array}{c}\text { Testing } \\
\text { techniques }\end{array}$ & $\begin{array}{c}\text { Usually Whitebox, } \\
\text { and Greybox }\end{array}$ & $\begin{array}{c}\text { Whitebox, and } \\
\text { Blackbox }\end{array}$ & $\begin{array}{c}\text { Usually Blackbox, } \\
\text { and Greybox }\end{array}$ & $\begin{array}{c}\text { Black-box testing } \\
\text { End-users }\end{array}$ \\
\hline Automation & $\begin{array}{c}\text { Automatable using } \\
\text { JUnit, PHPUnit, } \\
\text { TestNG etc. }\end{array}$ & $\begin{array}{c}\text { Automatable } \\
\text { using Soap UI, } \\
\text { Rest Client etc. }\end{array}$ & $\begin{array}{c}\text { Automatable using } \\
\text { Webdriver }\end{array}$ & $\begin{array}{c}\text { Automatable using } \\
\text { Cucumber }\end{array}$ \\
\hline Scaffolding & $\begin{array}{c}\text { Complex (require } \\
\text { drivers and/or stubs) }\end{array}$ & $\begin{array}{c}\text { Moderate (may } \\
\text { require drivers } \\
\text { and/or stubs) }\end{array}$ & $\begin{array}{c}\text { No drivers/stubs } \\
\text { required }\end{array}$ & $\begin{array}{c}\text { No drivers/stubs } \\
\text { required }\end{array}$ \\
\hline
\end{tabular}

\section{SOFTWARE TESTING TECHNIQUES}

These are the various techniques that are used in testing software to ensure it performs as expected. Testing techniques specifies the strategy used in developing test cases for conducting the testing and in analyzing test results [2] while increasing test coverage (since exhaustive testing is not possible) to achieve more effective testing. They help identify test conditions that are otherwise difficult to recognize. There are several testing techniques with each technique covering different aspects of software to reveal its quality. Utilizing all the testing techniques in testing a given software is not possible, but the tester can select and use more than one technique depending on the testing requirements, software type, budget and time constraint. The higher the number of testing techniques combines, the better the testing result, coverage and quality [21]. There are three essential testing techniques [13]: White-box, Black-box, and Grey-box testing. 


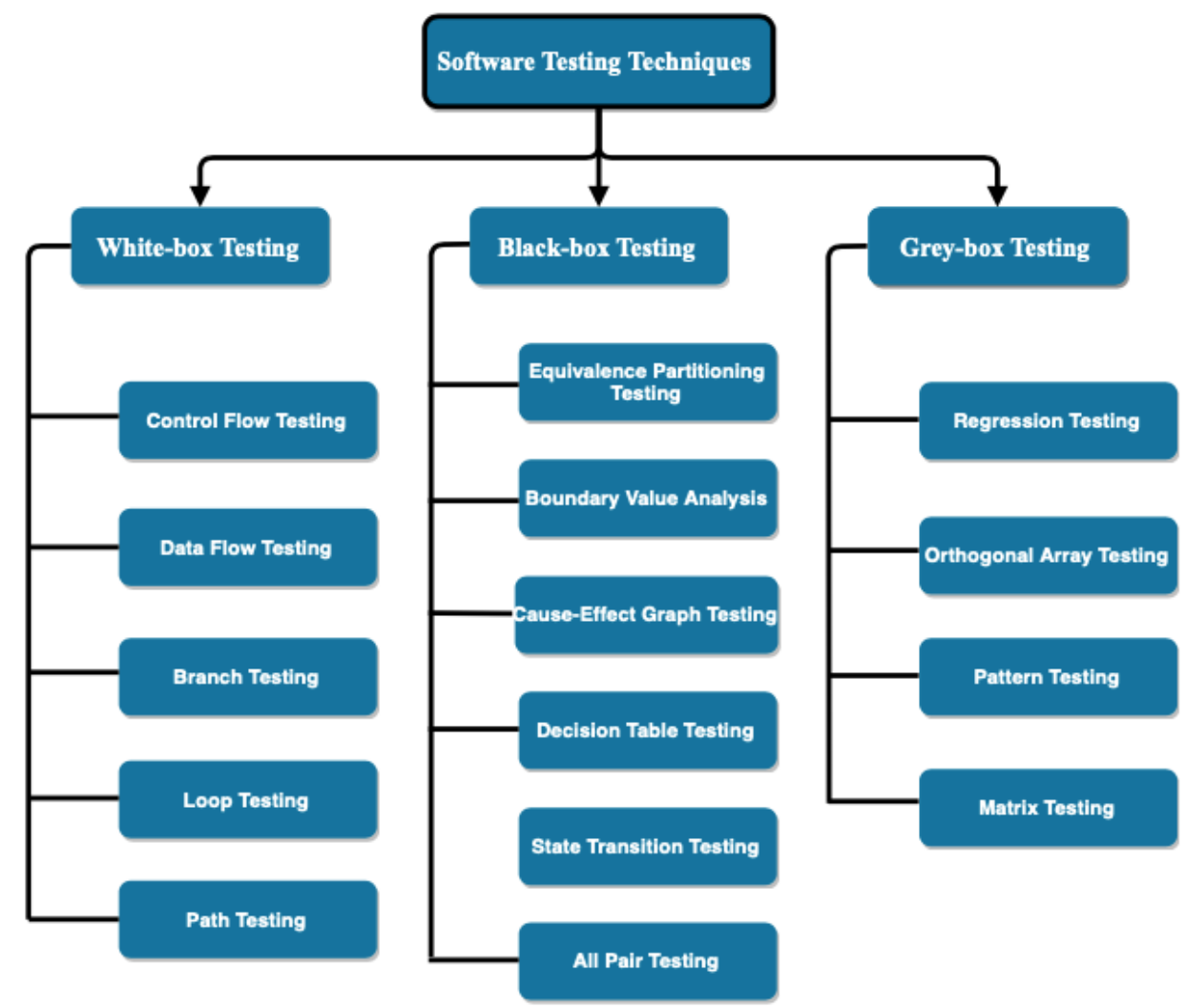

Figure 3: Software Testing Techniques

\subsection{WHITE-BOX TESTING}

This is a testing technique in which internal structure and implementation of software being tested are known to tester. In white box testing, full knowledge of source code is required because test cases selection is grounded on implementation of the software entity; internal view of the system, and tester's programming skills are used to design test cases [18]. Tester selects inputs to exercise program paths and compare the output with the expected output. White-box testing is also called Structural, Transparent Box, Glass Box, Clear Box, Logic Driven, Open Box Testing. White-box testing, although usually done at unit level, is also performed at integration and system levels of software testing process [13]. Some white-box testing types include: Control Flow, Data flow, Branch, Loop, Path Testing [13]. Some commonly used structural testing types are discussed below.

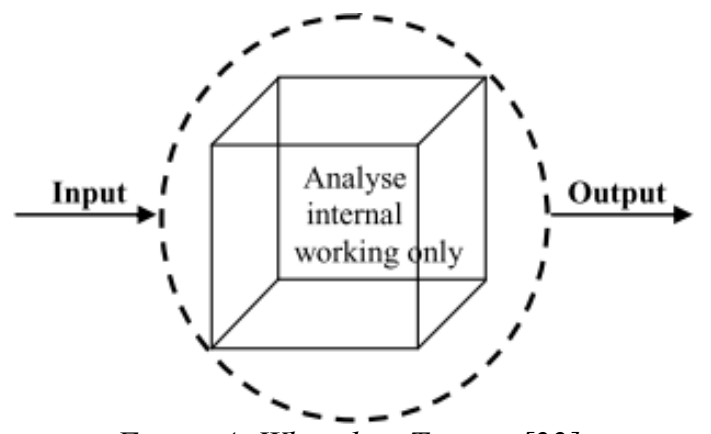

Figure 4: White-box Testing [22]

Table 2: Pros and Cons of White-box Testing

\begin{tabular}{|l|l|}
\hline Advantages & Disadvantages \\
\hline Code optimization can be performed & $\begin{array}{l}\text { Specialized tools are required such as debugging } \\
\text { tools and code analyzers. }\end{array}$ \\
\hline $\begin{array}{l}\text { Easy to identify data and cover more test cases due } \\
\text { to tester's knowledge of the code. }\end{array}$ & It's often expensive and difficult to maintain \\
\hline Errors in hidden codes are revealed & $\begin{array}{l}\text { Impossible to find and test all the hidden error and } \\
\text { deal with them without going out of time }\end{array}$ \\
\hline
\end{tabular}




\section{SOME COMMON WHITE-BOX TESTING TYPES \\ 4.1.1. CONTROL-FLOW TESTING}

Control flow testing is a type of white-box testing in which control flow graph (CFG) paths, nodes and conditions are selected, test cases are written for executing these paths, and each path, node or statements are traversed at least once to check the flow of control and determine order of execution. By examining the control structure, tester can select and design test cases [23]. Typically, a test case is an entire path from entry to exit nodes of the CFG. The selected set of paths is used to achieve a certain degree of testing thoroughness. Control-flow testing is most applicable to new software for unit testing [24].

A typical CFG of a program comprises of a set of nodes and edge, with each node representing a set of statements. There are five types of CFG nodes, viz.: unique entry and exit nodes, decision node (containing conditional statement that can have minimum of 2 control branches (such as switch or if statements)), then merge node (which mostly represent a point where multiple control branches merge), and statement node having a sequence of statements. The control must flow from the first statement and exit from the last statement, and the CFG may have an additional edge between nodes for the reverse order flow of control (i.e. from the last to the first statement) [25]. There are several conventions for flow graph models with subtle differences (e.g., hierarchical CFGs, concurrent CFGs). Control-flow testing support the following test coverage criteria [25]:

- Statement/Node Coverage: Executes each statement in the program at least once

- Edge Coverage: Executes each statement in the program at least once using all possible outcomes at least once on every decision in the program.

- Condition Coverage: Executes each statement in the program at least once using all possible outcomes at least once on every condition in each decision.

- Path Coverage: Executes each complete path in the program at least once. Except for loops, which usually has an infinite number of complete paths.

Table 3: Pros and Cons of Control-Flow Testing

\begin{tabular}{|l|l|}
\hline Advantages & Disadvantages \\
\hline Catches 50\% of all bugs caught during unit testing [24] & $\begin{array}{l}\text { Cannot detected specification errors as well as } \\
\text { Interface mismatches and mistakes }\end{array}$ \\
\hline $\begin{array}{l}\text { Very effective testing method for code that follows } \\
\text { unstructured programming }\end{array}$ & Cannot catch all initialization mistakes \\
\hline $\begin{array}{l}\text { Enable experienced testers to bypass drawing CFG by } \\
\text { doing path selection on the source }\end{array}$ & $\begin{array}{l}\text { Time consuming and required programing } \\
\text { knowledge }\end{array}$ \\
\hline
\end{tabular}

\subsubsection{DATA FLOW TESTING}

Data-flow testing is a type of white-box testing in which Control flow graph (CFG) paths are used to detect inappropriate definition or usage of data in predicates, computations, and termination (killing). It examines patterns in which a piece of data is used to identifies potential bugs [23]. Data flow testing searches for the unreasonable things that can happen to data. Data flow anomalies are identified based on the associations between variables and values (unused initialized variables or uninitialized used variables). Data flow testing focuses on variables definition, use occurrence, and both predicate and computational use at different points within the program. There are two main data flow testing forms:: (1) define/use testing, uses some simple rules and test coverage metrics; (2) program slices - uses segments of a program [26]. Data flow testing uses the following Test Coverage Criteria in creating test cases for the test [23]:

- All-defs $(A D)$ coverage: Has a path from every definition to at least one use of that definition

- All-uses $(A U)$ coverage: For every use of variable, there is atleast one path from the definition to its use.

- All-c-uses (ACU) coverage: For every variable, there is a path from each of its definition to each of its cuse. Any defined variable with no subsequent c-use is dropped from contention.

- All-c-uses/some-p-uses $(A C U+P)$ coverage: For every variable, there is a path from each of its definition to each of its c-use. If there is any defined variable with no c-use following it, then p-use is considered.

- All-p-uses (APU) coverage: For every variable, there is a path from each of its definition to each of its $p$ use Any defined variable with no subsequent p-use is dropped from contention.

- All-p-uses/some-c-uses $(A P U+C)$ coverage: For every variable, there is a path from each of its definition to each of its p-use. If there is any defined variable with no p-use following it, then c-use is considered.

- All-du-paths (ADUP) coverage: For each def-use pair, all paths between definitions and uses must be covered. It is the strongest data-flow testing strategy since it is a superset of all other data flow testing strategies. Moreover, this strategy requires greatest number of paths for testing. 
Table 4: Pros and Cons of Data-Flow Testing

\begin{tabular}{|l|l|}
\hline Advantage & Disadvantage \\
\hline $\begin{array}{l}\text { Can define intermediary Control flow analysis criteria } \\
\text { between all-nodes and all-paths testing }\end{array}$ & $\begin{array}{l}\text { Unscalable Data-Flow Analysis algorithm for large } \\
\text { real-world programs }\end{array}$ \\
\hline Handles variable definition and usage & $\begin{array}{l}\text { Test case design difficulties compared with control } \\
\text { flow testing. }\end{array}$ \\
\hline It spans the gap between all paths and branch testing & $\begin{array}{l}\text { Infeasible test objectives which might lead to wastage } \\
\text { of time on testing in vain [27]. }\end{array}$ \\
\hline Identify multiple variable declarations & Can have an infinite number of paths due to loops \\
\hline
\end{tabular}

\subsection{BLACK-BOX TESTING}

This is a software testing technique in which the internal structure/ implementation of software being tested is not known to the tester. It can be functional (such as integration testing) or non-functional (such as performance testing), though usually functional. Test cases are built around requirement specifications. In Black-box testing, emphasis is given on evaluating fundamental aspects of software using thorough test cases, and generally, on maintaining the integrity of external information [13]. For a given test case, tester verifies proper acceptance of inputs and correct production of outputs against test oracle. This testing can be applied at all levels of software testing processes such as Unit, Integration, System and Acceptance Testing levels, although done mostly on System testing and Integration testing. Black-box testing is also called Opaque, Functional, Specification-based, Close-box, Behavioral, and Input-Output testing. Some Black-box testing types include: Equivalence Partitioning, Cause-Effect Graph, Fuzzing, Boundary Value Analysis, Decision Table, State Transition, Orthogonal Array, and All Pair Testing [22]. Some common black-box testing types are discussed below.

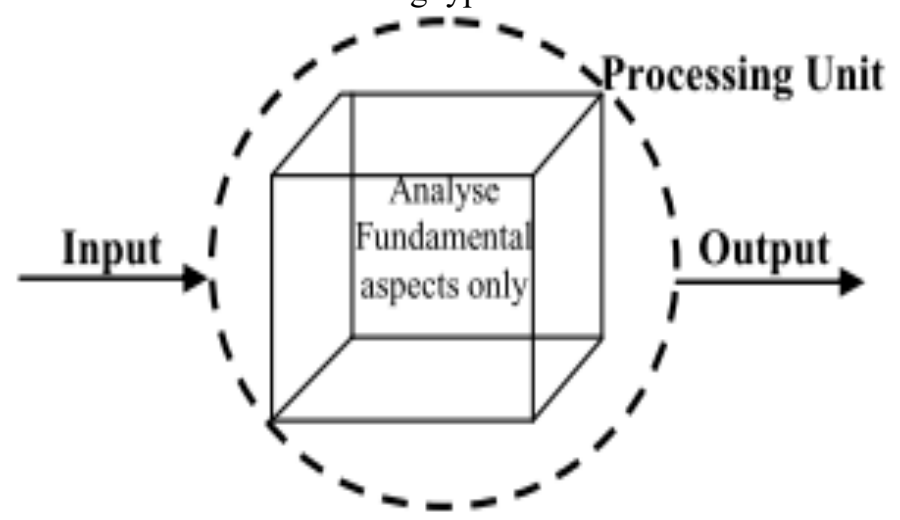

Figure 5: Black-box Testing [22]

Table 5: Pros and Cons of Black-box Testing

\begin{tabular}{|l|l|}
\hline Advantages & Disadvantages \\
\hline $\begin{array}{l}\text { Code knowledge is not required, tester's perception } \\
\text { is veryple }\end{array}$ & $\begin{array}{l}\text { Limited coverage, few test scenarios are } \\
\text { designed/performed. }\end{array}$ \\
\hline User's and developer's view are clearly separate & Some parts of the backend are not tested at all. \\
\hline $\begin{array}{l}\text { Access to code is unrequired, quicker test case } \\
\text { development }\end{array}$ & $\begin{array}{l}\text { Inefficient testing due to the limited knowledge of } \\
\text { code possess by tester. }\end{array}$ \\
\hline Efficient and suitable for large parts of code & $\begin{array}{l}\text { Test cases are difficult to design without clear } \\
\text { specification }\end{array}$ \\
\hline
\end{tabular}

\section{SOME COMMON BLACK-BOX TESTING TYPES}

\subsubsection{EQUIVALENCE PARTITIONING TESTING (EP)}

The testing technique of dividing input domain of a program into different equivalence classes to reduce the number of test cases. One element from each equivalence class (EC) is then selected as test cases. This method is used to avoid test redundancy and give a sense of complete testing. EC Testing can be weak or strong. In Weak Equivalence Class Testing (WECT), number of test cases is defined by chosen one variable value from each equivalence class and then taking the maximum value from the chosen variables, while test cases in Strong Equivalence Class Testing (SECT) is based on cartesian product of partition class, i.e., testing all interactions of all equivalence classes [28]. 
Table 6: Pros and Cons of Equivalence Partitioning Testing

\begin{tabular}{|l|l|}
\hline Advantages & Disadvantages \\
\hline $\begin{array}{l}\text { Provide sense of complete testing and eradicates the } \\
\text { need for exhaustive testing }\end{array}$ & $\begin{array}{l}\text { Suitable only for range-wise and discrete values input } \\
\text { data }\end{array}$ \\
\hline $\begin{array}{l}\text { Enables large domain of inputs or outputs coverage } \\
\text { with a smaller subset selected from an equivalence } \\
\text { class }\end{array}$ & $\begin{array}{l}\text { Assumes that the data in the same equivalence class is } \\
\text { processed in the same way by the system }\end{array}$ \\
\hline $\begin{array}{l}\text { Avoid test redundancy by selecting a subset of test } \\
\text { inputs from each class. }\end{array}$ & $\begin{array}{l}\text { Can't handle boundary value errors. Need to be } \\
\text { supplemented by boundary value analysis }\end{array}$ \\
\hline
\end{tabular}

\subsubsection{BOUNDARY VALUE ANALYSIS TESTING (BVA)}

This is a black box test selection technique that aims at finding software errors at boundaries of equivalence classes. Unlike the Equivalence Partitioning technique (uses only input domain), BVA uses both input and output domains in creating test cases. BVA complements EP in such that while EP selects tests from within equivalence classes, BVA focuses on tests at and near the boundaries of equivalence classes [28]. Tests derived using either of the two techniques may overlap.

Table 7: Pros and Cons of Boundary Value Analysis Testing

\begin{tabular}{|l|l|}
\hline Advantages & Disadvantages \\
\hline $\begin{array}{l}\text { Complements Equivalence Partitioning testing by } \\
\text { handling equivalence class boundary errors. }\end{array}$ & Generate high number of test cases \\
\hline $\begin{array}{l}\text { Works well with variables that represent bounded } \\
\text { physical quantities }\end{array}$ & Can't be used for Boolean and logical variables \\
\hline $\begin{array}{l}\text { Can be used at unit, integration, system and } \\
\text { acceptance test levels }\end{array}$ & $\begin{array}{l}\text { Function nature and variable meaning are not } \\
\text { considered }\end{array}$ \\
\hline Computationally less costly in creating test cases & Not that useful for strongly-typed languages \\
\hline
\end{tabular}

\subsection{GREY-BOX TESTING}

Grey-box (translucent) testing technique that takes the straightforward technique of black-box testing and combines it with the code-targeted systems in white-box testing. Some knowledge of the internal working of the software is required (usually of the part to be tested) in designing tests at black-box level. More understanding of internals of software is required in grey-box testing than in black box testing, but less compared to white box testing [13]. Gray box testing is much more effective in integration testing and is best approach for functional or domain testing, also a perfect fit for Web-based applications [29]. Some grey-box testing types include: Orthogonal Array, Regression, Pattern and Matrix Testing. Some of these testing are discussed.

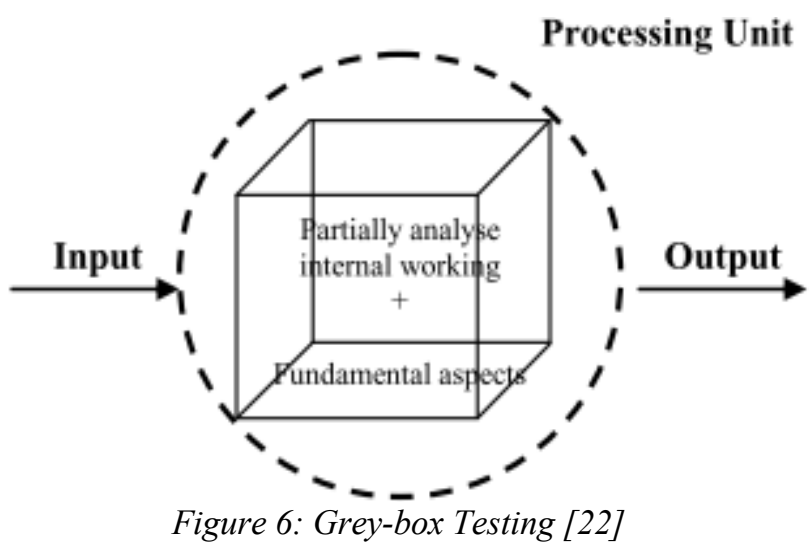

Table 8: Pros and Cons of Grey-box Testing

\begin{tabular}{|l|l|}
\hline Advantages & Disadvantages \\
\hline $\begin{array}{l}\text { Provides combined benefits of both white-box and } \\
\text { black-box testing }\end{array}$ & $\begin{array}{l}\text { Complete white-box testing cannot be done due to } \\
\text { inaccessible source code/binaries }\end{array}$ \\
\hline $\begin{array}{l}\text { Can handle design of complex test scenario more } \\
\text { intelligently }\end{array}$ & Defect association is difficult in distributed systems. \\
\hline $\begin{array}{l}\text { Maintain boundary between independent testers and } \\
\text { developers }\end{array}$ & Gray box testing is not suitable for algorithm testing. \\
\hline
\end{tabular}




\section{SOME COMMON GREY-BOX TESTING TYPES}

\subsubsection{REGRESSION TESTING}

Regression testing is a grey-box testing strategy that is performed every time changes are made to the software to ensure that the changes behave as intended and that the unchanged part is not negatively affected by the modification. Errors that occurred at unchanged parts of software are called regression errors. Regression testing starts with a (possibly modified) specification, a modified program, and an old test plan (which requires updating) [30].

\section{Table 9: Pros and Cons of Regression Testing}

\begin{tabular}{|l|l|}
\hline Advantages & Disadvantages \\
\hline $\begin{array}{l}\text { Tests can be automated thereby saving time and } \\
\text { improving quality of software. }\end{array}$ & $\begin{array}{l}\text { Tedious and time consuming if done without } \\
\text { automated tools }\end{array}$ \\
\hline $\begin{array}{l}\text { It ensures that a fix doesn't adversely affect the } \\
\text { working functionality. }\end{array}$ & $\begin{array}{l}\text { Testing is required even on making slight changes to } \\
\text { program }\end{array}$ \\
\hline Improves and maintain software quality & $\begin{array}{l}\text { One of the main causes of software maintenance } \\
\text { expensiveness. }\end{array}$ \\
\hline
\end{tabular}

\subsubsection{ORTHOGONAL ARRAY TESTING (OAT)}

This is a type of testing that uses pair-wise combinations of data or entities as test input parameters to increase the scope. The selected pairs of parameters should be independent of one another. OAT is handy when maximum coverage is required with minimum test cases and a huge number of test data having many permutations and combinations. It's extremely valuable for testing complex applications and e-comm products [31].

\section{Table 10: Pros and Cons of Orthogonal Array Testing (OAT)}

\begin{tabular}{|l|l|}
\hline Advantages & Disadvantages \\
\hline $\begin{array}{l}\text { Test pair-wise combinations of all the selected } \\
\text { variables }\end{array}$ & $\begin{array}{l}\text { Increase in Test case complexity as input data } \\
\text { increases }\end{array}$ \\
\hline $\begin{array}{l}\text { Creates fewer Test cases which cover the testing of all } \\
\text { the combination of all variables. }\end{array}$ & Tedious and time consuming if done manually. \\
\hline $\begin{array}{l}\text { Improves productivity because of reduced test cycles } \\
\text { and testing times. }\end{array}$ & \\
\hline
\end{tabular}

\section{COMPARISON OF SOFTWARE TESTING TECHNIQUES}

There is no one particular technique that is better, however, depending on the testing requirements and needs one technique can have some advantages over others and vice. In testing any software, exploring and combining many testing techniques helps in eliminating more bugs thereby increasing the overall quality of the software than sticking to one technique. The table below presents comparisons of the three discussed testing techniques using some criteria.

\section{Table 11: Comparison of Testing Techniques}

\begin{tabular}{|l|l|l|l|}
\hline Criteria & White-box & Black-box & Grey-box \\
\hline $\begin{array}{l}\text { Required } \\
\text { knowledge }\end{array}$ & $\begin{array}{l}\text { Full knowledge of internal } \\
\text { working of software. }\end{array}$ & $\begin{array}{l}\text { Knowledge of internal } \\
\text { working of software is not } \\
\text { required. }\end{array}$ & $\begin{array}{l}\text { Limited knowledge of the } \\
\text { internal workings of software. }\end{array}$ \\
\hline Performed by & $\begin{array}{l}\text { Usually testers and } \\
\text { developers. }\end{array}$ & $\begin{array}{l}\text { End-users, developers, and } \\
\text { testers }\end{array}$ & $\begin{array}{l}\text { End-users, developers, and } \\
\text { testers }\end{array}$ \\
\hline Testingfocus & $\begin{array}{l}\text { Internal workings, coding } \\
\text { structure, and flow of data } \\
\text { and control. }\end{array}$ & $\begin{array}{l}\text { Evaluating fundamental } \\
\text { aspects of the software }\end{array}$ & $\begin{array}{l}\text { High-level database diagrams } \\
\text { and data flow diagrams. }\end{array}$ \\
\hline Granularity & High & Low & Medium \\
\hline $\begin{array}{l}\text { Time } \\
\text { consumption }\end{array}$ & $\begin{array}{l}\text { Very exhaustive and time- } \\
\text { consuming }\end{array}$ & $\begin{array}{l}\text { Exhaustive and the least } \\
\text { time-consuming. }\end{array}$ & $\begin{array}{l}\text { Partly time-consuming and } \\
\text { exhaustive. }\end{array}$ \\
\hline $\begin{array}{l}\text { Data domain } \\
\text { testing }\end{array}$ & $\begin{array}{l}\text { Data domains and internal } \\
\text { boundaries can be better } \\
\text { tested. }\end{array}$ & $\begin{array}{l}\text { Can be performed through } \\
\text { trial-and-error method. }\end{array}$ & $\begin{array}{l}\text { Can be done on identified } \\
\text { Data domains and internal } \\
\text { boundaries }\end{array}$ \\
\hline $\begin{array}{l}\text { Algorithm } \\
\text { testing }\end{array}$ & $\begin{array}{l}\text { Suitable for testing } \\
\text { algorithms. }\end{array}$ & $\begin{array}{l}\text { Unsuitable for testing } \\
\text { algorithm. }\end{array}$ & $\begin{array}{l}\text { Inappropriate for testing } \\
\text { algorithms. }\end{array}$ \\
\hline Also known as & $\begin{array}{l}\text { Transparent-box, Open-box, } \\
\text { Logic-driven, or code-based } \\
\text { testing. }\end{array}$ & $\begin{array}{l}\text { Closed-box, data-driven, } \\
\text { functional, or Specification- } \\
\text { based testing. }\end{array}$ & Translucent testing \\
\hline
\end{tabular}




\section{SOFTWARE TESTING TYPES}

Testing Types: are the various testing that are performed at a particular test level based on a proper test technique to address testing requirements in the most effective manner [12]. There are many types of testing each serving different purposes. In a survey conducted by International Software Testing Qualifications Board (ISTQB) [32], some of the most important types of testing are:

Table 12: Software Testing Types

\begin{tabular}{|l|l|l|l|}
\hline Testing Type & Object & Technique Type & Testing Level \\
\hline Functional Testing & Test functions of software & Blackbox testing & $\begin{array}{l}\text { Acceptance } \\
\text { and System level }\end{array}$ \\
\hline Performance Testing & $\begin{array}{l}\text { Testing software responsiveness } \\
\text { and stability under a particular } \\
\text { workload }\end{array}$ & Blackbox testing & Any level \\
\hline Security Testing & $\begin{array}{l}\text { Protect data and maintain } \\
\text { software functionality }\end{array}$ & Whitebox testing & Any Level \\
\hline Usability Testing & Check ease of use of software & Blackbox testing & $\begin{array}{l}\text { Acceptance } \\
\text { and System level }\end{array}$ \\
\hline Use case Testing & $\begin{array}{l}\text { Checking that path used by user } \\
\text { is working as intended }\end{array}$ & Blackbox testing & $\begin{array}{l}\text { Acceptance, System } \\
\text { and Integration level }\end{array}$ \\
\hline Exploratory Testing & Validate experience of user & Ad-hoc testing & $\begin{array}{l}\text { Acceptance } \\
\text { and System level }\end{array}$ \\
\hline
\end{tabular}

\section{CONCLUSION}

Delivering quality software is the main goal of any software project. Software Testing has been widely used and remains the truly effective means of assuring the quality of software. In this paper, some important software testing concepts, their advantages and disadvantages are discussed, comparisons of software testing techniques and software testing levels are presented. Learning about and successful usage of these software testing methods in software development will help testers carry out software testing in a more effective manner thereby improving software quality.

\section{REFERENCES}

[1] A. Dennis, B. H. Wixom, and D. Tegarden, Systems Analysis and Design with OOP Approach with UML 2.0, 4th Editio. USA: John Wiley \& Sons, Inc., 2009.

[2] L. Luo, 'A Report on Software Testing Techniques', Pittsburgh, USA.

[3] G. J. Myers, C. Sandler, and T. Badgett, The Art of Software Testing 3rd Edition, Third Edit. Canada.: John Wiley \& Sons, Inc., 2012.

[4] D. R. Graham, 'TESTING, VERIFICATION AND VALIDATION', Int. J., vol. XVI, pp. 1069-1101, 1979.

[5] E. Miller, Software testing \& validation techniques. [Washington D.C.]: IEEE Computer Society Press, 1981.

[6] A. Dennis, B. H. Wixom, and R. M. Roth, Systems Analysis and Design 5th Edition, 5th Editio. USA: John Wiley \& Sons, Inc., 2012.

[7] S. Rogerson, 'The Chinook Helicopter Disaster', 2002. [Online]. Available: https://www5.in.tum.de/ huckle/chinook_software.pdf.

[8] N. I. of S. andTechnology (NIST), 'Software Errors Cost U.S. Economy \$59.5 Billion Annually: NIST Assesses Technical Needs of Industry to Improve Software-Testing', Web.archive.org, 2002. [Online]. Available:

https://web.archive.org/web/20090610052743/http://www.nist.gov/public affairs/releases/n02-10.htm.

[Accessed: 11-May-2019].

[9] C. Jones, 'Software Quality in 2012: a Survey of the State of the Art', 2012.

[10] B. W. Boehm, Software engineering economics. Englewood Cliffs, N.J.: Prentice-Hall, 1981.

[11] P. Ammann and J. Offutt, Introduction to Software Testing. Cambridge University Press, 2008.

[12] Altexsoft, 'Quality Assurance - Quality Control and Testing: The Basics of Software Quality Management', Kharkiv, Ukraine, 2016.

[13] E. Khan, 'Different Forms of Software Testing Techniques for Finding Errors', Int. J. Comput. Sci. Issues, vol. 7, no. 3, pp. 11-16, 2010.

[14] K. Sneha and G. M. Malle, 'Research on software testing techniques and software automation testing tools', 2017 Int. Conf. Energy, Commun. Data Anal. Soft Comput. ICECDS 2017, pp. 77-81, 2017.

[15] M. A. Jamil, M. Arif, N. Sham, A. Abubakar, and A. Ahmad, 'Software Testing Techniques : A Literature Review', no. November, 2016.

[16] P. Borba, Testing techniques in software engineering: Second Pernambuco Summer School on Software Engineering, PSSE 2007, Recife, Brazil, December 3-7, 2007, Revised Lectures. Springer-Verlag, 2010. 
[17] C. Padmini, '1- Beginners Guide To Software Testing', pp. 1-41, 2013.

[18] S. Nidhra and J. Dondeti, 'Black Box and White Box Testing Techniques', Int. J. Embed. Syst. Appl., vol. 2, no. 2, pp. 29-50, 2012.

[19] 'Software Testing - Wikipedia'. [Online]. Available: https://en.wikipedia.org/wiki/Software_testing. [Accessed: 05-May-2019].

[20] R. V. Binder, Testing Object-Oriented Systems: Objects, Patterns, and Tools. Addison-Wesley Professional, 1999.

[21] I. Jovanovic, 'Software Testing Methods and Techniques', IPSI BgD Trans. Internet Res., vol. 5, no. 1, pp. 30-41, 2009.

[22] Mohd. Ehmer Khan and Farmeena Khan, 'A Comparative Study of White Box, Black Box and Grey Box Testing Techniques', Int. J. Adv. Comput. Sci. Appl., vol. 3, no. 6, pp. 12-15, 2012.

[23] J. Badlaney, R. Ghatol, and R. Jadhwani, 'An Introduction to Data-Flow Testing', Control, pp. 1-8, 2006.

[24] S. Mancoridis, 'CS576 Dependable Software Systems - Topics in Control-Flow Testing'. [Online]. Available: https://www.cs.drexel.edu/ spiros/teaching/CS576/slides/2.control-testing.pdf. [Accessed: 05May-2019].

[25] N.-W. Lin, 'Software Testing (CS5812) - Control Flow Testing'. [Online]. Available: https://www.cs.ccu.edu.tw/ naiwei/cs5812/st4.pdf.

[26] M. New, 'Data Flow Testing Swansea University UK'.

[27] T. Su et al., A Survey on Data-Flow Testing, vol. 50, no. 1. 2017.

[28] L. Briand, 'Software Verification and Validation - WBT', 2010. [Online]. Available: https://www.uio.no/studier/emner/matnat/ifi/nedlagteemner/INF4290/v10/undervisningsmateriale/INF4290-WBT.pdf. [Accessed: 03-May-2019].

[29] 'Software Testing Class - Grey box'. [Online]. Available: https://www.softwaretestingclass.com/graybox-testing/.

[30] L. Briand, 'Software Verification and Validation (INF4290) - Regression Testing', 2010. [Online]. Available: $\quad$ https://www.uio.no/studier/emner/matnat/ifi/nedlagteemner/INF4290/v10/undervisningsmateriale/INF4290-RegTest.pdf.

[31] Alex Samurin, 'Explore the World of Gray Box Testing', 2003. [Online]. Available: http://extremesoftwaretesting.com/Articles/WorldofGrayBoxTesting.html. [Accessed: 19-May-2019].

[32] ISTQB, 'Worldwide Software Testing Practices Report'.

International Software Testing Qualifications Board (ISTQB) (2017). Worldwide Software Testing Practices Report. [online] ISTQB, pp.1-40. Available at: https://www.istqb.org/documents/ISTQB 201718_Revised.pdf [Accessed 21 May 2019]. 